\title{
A Cartomante: do triângulo amoroso machadiano à trama argumentativa
}

\author{
Andréia Inês Hanel Cerezoli \\ Docente da Universidade Federal Fronteira Sul (UFFS), Brasil \\ hanelandreia@gmail.com
}

\section{Carina Maria Melchiors Niederauer}

Docente da Universidade de Caxias do Sul (UCS), Brasil

carina.nider@gmail.com

Resumo: O presente estudo busca mostrar como os pressupostos da Teoria da Polifonia, de Ducrot (1980; 1987), podem colaborar com a descrição e a explicação da presença de diferentes vozes na constituição do sentido do discurso. A fundamentação teórica deste estudo está alicerçada em Ducrot (1980; 1987) idealizador e pesquisador da Semântica Argumentativa (SA) ou Teoria da Argumentação na Língua (TAL). A seleção desse referencial teórico justifica-se, porque a versão mais atual da Teoria da Polifonia ainda está sendo testada e validada, enquanto a versão selecionada demonstra grande potencial à descrição semântica de discursos, como sugere Azevedo (2019). Aplica-se, nesta investigação o método da simulação proposto por Ducrot, que consiste na observação, descrição e explicação do sentido do discurso para chegar à significação na língua. A descrição polifônica do discurso permite explicar, por exemplo, a trama de vozes presentes no discurso que evidencia a argumentação do locutor.

Palavras-chave: Compreensão leitora. Teoria da Polifonia. Argumentação. Sentido.

Abstract: The present study seeks to show how the assumptions of Ducrot 's Theory of Polyphony can collaborate with the reader to understand the argumentative process that is established in the discourse, allowing certain continuations, both the speaker and the speaker, and preventing others. The theoretical basis of this study is based on Ducrot, idealizer and researcher of Argumentative Semantics (SA) or Theory of Argumentation in Language (TAL), as well as in Barbisan and Teixeira. In this investigation the method of the simulation proposed by Ducrot, which consists in the observation, description and explanation of the meaning of the discourse to reach meaning in the language, is applied in this investigation. The polyphonic description of the discourse allows to explain, for example, the plot of voices present in the discourse that evidences the speaker's argumentation.

Keywords: Reading comprehension. Polyphony theory. Argumentation. Meaning. 


\section{Introdução}

Machado de Assis, como todos sabem, é considerado um dos maiores nomes da literatura brasileira e, pensando numa perspectiva semânticoargumentativa, um escritor que conseguiu perceber o princípio argumentativo da língua, como pode ser comprovado, por exemplo, no conto A Cartomante. Nele, ao narrar o encontro de Rita e Camilo, descrevendo Camilo como um descrente de superstições: "Camilo não acreditava em nada. Por quê? Não poderia dizê-lo, não possuía um só argumento; limitava-se a negar tudo. E digo mal, porque negar é ainda afirmar [...]" (ASSIS, 2000, grifo nosso) anuncia um dos aspectos polifônicos do discurso muito antes de Oswald Ducrot e JeanClaude Anscombre formularem a Teoria da Argumentação na Língua (TAL), na década de $60^{1}$, cuja ideia fundamental é a de que "[... ] a argumentação está inscrita na língua, nas próprias frases." (ANSCOMBRE; DUCROT, 1994, p. 18, tradução nossa).

Enquanto a escrita machadiana apresenta um tema recorrente em suas obras, triângulos amorosos - nas quais a capacidade literária do autor assegura, por exemplo, o suspense acerca da traição de Capitu, em Dom Casmurro, há mais de um século -, Ducrot persegue e descreve, há trinta anos, uma outra trama, menos evidente, mas tão envolvente quanto os casos amorosos machadianos, uma trama linguística: a polifonia enunciativa. Partindo, então, dos fundamentos teóricos postulados por Ducrot e Anscombre (1980; 1987) acerca da Teoria da Polifonia, este artigo busca mostrar como tais pressupostos podem colaborar com a descrição e a explicação da presença de diferentes vozes na constituição do sentido do discurso.

A fim de mostrar como os diferentes pontos de vista habitam o texto machadiano, tem-se como recorte, considerando os limites de extensão impostos a um artigo, a fala de dois dos personagens de $A$ Cartomante.

A justificativa para uma investigação dessa natureza se deve ao fato de possibilitar, ao descrever e explicar fenômenos discursivos, o avanço dos estudos sobre semântica e argumentação.

\footnotetext{
${ }^{1}$ Barbisan (2012) afirma que a Teoria da Argumentação na Língua tem um longo desenvolvimento, sendo difícil apontar com exatidão a data de seu início. Sugere que os princípios da Teoria surgem ainda em 1960, quando Ducrot adota o conceito de valor.
} 
O artigo está organizado da seguinte maneira: primeiramente são explicitados alguns dos fundamentos da Teoria da Argumentação da Língua (TAL); em seguida é apresentada a Teoria da Polifonia; e, por fim, é feita a análise polifônica, a partir de um recorte do conto A Cartomante, de Machado de Assis.

\section{A argumentação está na língua}

Uma pesquisa científica inicia por escolhas tanto epistemológicas quanto metodológicas. Sendo assim, iniciamos apresentando os objetivos deste estudo, que são: (1) justificar e definir o fundamento basilar da Semântica Argumentativa, a saber: o de que a argumentação está na língua; e (2) expor os fundamentos da Teoria da Polifonia, detalhando, mais especificamente, as noções de pressuposição e de negação.

Para que se possa compreender a tese da Semântica Argumentativa, que é "a argumentação está na língua", é preciso fazer um "sobrevoo" às suas origens. Ducrot afirma que esta é uma teoria semântica voltada a refutar o Logicismo: "Nossa ideia central é a de que a significação das palavras se constitui pelas argumentações." (DUCROT, 2012, p. 15-16). Para o semanticista, as argumentações não são raciocínios para permitir a passagem de certo conhecimento a outro: “Então, nós refutamos, por um lado, a visão convencional do ato de argumentar e, por outro lado, defendemos a ideia de que a argumentação está primeiramente no próprio sentido ${ }^{2}$ das palavras e que ela não é um tipo de consequência do uso das palavras." (DUCROT, 2012, p. 15-16). Vejamos um exemplo.

Imaginemos a expressão é tarde! empregada no seguinte discurso: (1) a menina cresceu, portanto, é tarde para convidá-la a brincar. Nesse caso, é tarde! terá o sentido de tempo da infância; já, no seguinte discurso: (2) é tarde para chegar, a prova já começou, - é tarde! terá o sentido de tempo de início de uma atividade. Como se vê nesses exemplos, é tarde! terá seu sentido modificado, respeitando a orientação argumentativa dada pela significação linguística.

Além de refutar o Logicismo, Ducrot esclarece que a TAL se opõe radicalmente à concepção tradicional de argumentação. Nessa perspectiva,

\footnotetext{
2 Segundo a Semântica Argumentativa, as palavras, as frases e os textos contêm "significações", e os enunciados e discursos são as entidades portadoras de "sentido".
} 
um discurso contém uma argumentação quando são satisfeitas três condições: (1) apresentar dois segmentos cuja ordem em que se apresentam é indiferente, A (argumento) e C (conclusão); (2) o A (argumento) indica um fato (F). O argumento (A) pode ser verdadeiro ou falso, mas tem valor de verdade independentemente de $C$ (conclusão); e (3) a conclusão (C) pode ser inferida a partir do fato (F). Ducrot (1990, p. 75) defende que, segundo essa concepção, "[...] a língua desempenha um papel muito reduzido na argumentação." 3 e apresenta a concepção de argumentação marcada na língua. Para ele: "[...] a conclusão não se explica somente a partir do fato expresso pelo segmento A, mas através da forma linguística de A. Em outras palavras, a argumentação está marcada na própria língua."4 (DUCROT, 1990, p. 80, tradução nossa). Exemplificamos, nos enunciados (3) e (4), como a argumentação está marcada na língua. Imaginemos uma situação na qual se admite que, para guiar um carro com segurança, o condutor deva estar descansado, sem sono.

\section{(3) João não dormiu}

Esse enunciado permite continuações como: portanto "pode sofrer algum acidente" ou "não deveria viajar", mas impede continuações como: portanto "pode dirigir" ou "terá uma viagem tranquila", que são autorizadas pelo enunciado (4).

(4) João dormiu

Nos dois enunciados, trata-se do mesmo fato, João ter ou não descansado, mas a intenção do locutor, ao mobilizar um ou outro enunciado, não é a mesma. Em (3), argumenta a favor de uma conclusão negativa quanto a guiar um carro, já em (4) leva a uma conclusão totalmente oposta.

Feitas essas considerações, passamos agora a outros conceitos necessários para que se possa entender a polifonia ducrotiana. Para compreendê-los é preciso saber a oposição feita por Ducrot ao conceito de unicidade do sujeito falante, a qual expõe no primeiro capítulo da obra Polifonía y Argumentación: conferencias del seminario Teoría de la Argumentación y Análisis del Discurso (1990). De acordo com essa concepção,

\footnotetext{
${ }^{3}$ No original: “[... ] la lengua desempeña un papel muy reducido en la argumentación.”

${ }^{4}$ No original: "la conclusión no se explica solamente a partir del hecho expresado por el segmento A, sino a través de la forma linguística de A. En otras palabras, la argumentación está marcada en la lengua misma."
} 
por trás de cada enunciado há apenas uma pessoa. Em oposição a essa ideia, Ducrot apresenta a Teoria da Polifonia, na qual afirma que, em um enunciado, estão presentes diferentes vozes com status linguísticos diferentes, são elas: (1) sujeito empírico (SE); (2) locutor (L); e (3) enunciador (E). Mas como atuam essas figuras discursivas em um enunciado/discurso?

De acordo com Ducrot (1990, p. 16, tradução nossa): “O sujeito empírico (SE) é o autor efetivo, o produtor do enunciado" 5 . Contudo, determinar o autor efetivo de um enunciado/discurso, é menos fácil do que se imagina. Vejamos, no discurso (5), uma situação comum: a fofoca. Quem seria o autor efetivo de uma possível calúnia como a feita em (5)?

(5) Maria disse que a vizinha $X$ traiu o marido. Foi Joana que me contou!

Nesse enunciado há alguém que diz que Maria disse que a vizinha $X$ traiu o marido, mas que foi Joana que contou para esse alguém. Esse é um exemplo clássico da dificuldade de reconhecer quem é o sujeito empírico. Ao analisarmos esse discurso por meio da polifonia ducrotiana, o que temos de explícito é o locutor (figura discursiva) que se responsabiliza pelo que está sendo dito neste momento.

Para Ducrot, a determinação do sujeito empírico (SE) não é um problema linguístico, porque o que interessa ao linguista semanticista é o que está no enunciado e não suas condições externas, o autor "carne e osso" do enunciado.

Quanto ao locutor (L), segundo Ducrot (1990), é a figura discursiva a quem se atribui a responsabilidade da enunciação; no entanto, o locutor (L) pode ser totalmente diferente do sujeito empírico $(\mathrm{SE})^{6}$. Imaginemos a seguinte situação: a esposa flagra mensagens românticas de outra mulher no celular do marido e diz:

(6) Não tenho mais ninguém, amor!

Nesse caso, quem é o eu? Certamente, não a esposa traída, mas o traidor que deveria, no mínimo, ficar constrangido. Desconsiderando o mundo extralinguístico, discursivamente "eu" designa um locutor (L), isto é, aquele

\footnotetext{
${ }^{5}$ No original: "El sujeto empírico SE es el autor efectivo, el productor del enunciado."

${ }^{6}$ No original: "Para maiores detalhes das diferenças entre sujeito empírico (SE) e locutor (L), ver Benveniste, A natureza dos pronomes."
} 
que se responsabiliza pelo discurso proferido, independentemente de quem seja o sujeito empírico (SE).

Uma das vantagens de se distinguir o locutor (L) do sujeito empírico (SE) é poder "[...] conceder a palavra a seres que são incapazes de falar."7 (DUCROT, 1990, p. 18, tradução nossa) como, por exemplo, na era dos pets, em que é comum encontrarmos animais de estimação, principalmente cachorros, passeando com seus donos, em locais públicos, e que, algumas vezes, fazem suas necessidades fisiológicas em canteiros de flores, muros e vitrines de lojas. Nesses casos, é comum depararmo-nos com avisos do tipo:

(7) Não sou seu banheiro!

Discursivamente, sou, poderia remeter a canteiro de flores, muro ou vitrine, e qualquer um desses lugares poderia ser o locutor (L) que, certamente, não é o autor do enunciado, o sujeito empírico (SE).

O enunciador (E), por sua vez, é a origem dos pontos de vista que se apresentam em um enunciado. Não esquecendo que um enunciado apresenta, no mínimo, dois enunciadores que: "Não são pessoas, mas 'pontos de vista' abstratos."8 (DUCROT, 1990, p. 20, tradução nossa). O locutor (L) pode tomar diferentes atitudes em relação aos enunciadores, como será explicado mais adiante.

A partir desse "sobrevoo" sobre a TAL, é possível entender não apenas sua tese fundadora, segundo a qual a "argumentação está na língua", mas também confirmar a proposição ducrotiana de que "[...] a argumentação discursiva não tem nenhum caráter racional, ela não fornece justificação, nem mesmo esboços fracos, lacunares, de justificação." (DUCROT, 2009, p. 21).

Na sequência, apresentamos a Teoria da Polifonia, que é parte da Teoria da Argumentação na Língua.

\subsection{A Teoria da Polifonia}

Para abordar a concepção polifônica de sentido, partimos de três obras ducrotianas: Les mots du discours (1980); O dizer e o dito (1987); e Polifonía y Argumentación: conferencias del seminario Teoría de la Argumentación y

\footnotetext{
${ }^{7}$ No original: "[... ] conceder la palabra a seres que son incapaces de hablar."

${ }^{8}$ No original: "No son personas sino 'puntos de perspectiva' abstractos."
} 
Análisis del Discurso (1990), uma vez que a Teoria da Polifonia, em sua última versão, ainda está em elaboração.

Em sua origem, "a noção de polifonia refere-se a uma classe de composição musical na qual se sobrepõem diferentes partituras."9 (DUCROT, 1990, p. 15, tradução nossa). Segundo Ducrot, a partir da música, Bakhtin, por exemplo, adapta a noção de polifonia para caracterizar duas formas de literatura: (a) a dogmática, “[... ] uma literatura na qual se expressa uma só voz, a do autor [...]"10 (DUCROT, 1990, p. 15, tradução nossa) e (b) a polifônica, “[...] literatura que qualifica de popular, polifônica, ou carnavalesca, e na qual existem vários personagens que se apresentam por si mesmos, como as máscaras de carnaval."11 (DUCROT, 1990, p. 15, grifos do autor, tradução nossa). Ao adaptar a noção de polifonia às análises linguísticas de enunciados, Ducrot (1990, p. 16, tradução nossa) considera que "[...] o autor de um enunciado não se expressa nunca diretamente, mas põe em cena no mesmo enunciado um certo número de personagens." ${ }^{12}$, e o sematicista “[...] opera o conceito num nível lingüístico, indicando, através dele, a possibilidade de um desdobramento enunciativo dentro do próprio enunciado." (BARBISAN; TEIXEIRA, 2002, p. 162).

A ideia central da Teoria da Polifonia consiste em afirmar que "[... ] em um mesmo enunciado estão presentes vários sujeitos com status linguísticos diferentes"13 (DUCROT, 1990, p. 16, tradução nossa), tese que define a argumentação a partir das indicações que a frase dá sobre as relações entre os interlocutores: "[...] a frase, e portanto a língua, contém alusões à atividade de fala, contém alusões sobre o que fazemos quando falamos." ${ }^{14}$ (DUCROT, 1990, p. 64, tradução nossa).

\footnotetext{
${ }^{9}$ No original: "Originalmente la noción de polifonía se refiere a una clase de composición musical en la cual se superponen diferentes partituras."

${ }^{10}$ No original: "[... ] una literatura en la cual se expresan bien sea una sola voz, la del autor [...]"

${ }^{11}$ No original: "[...] literatura que califica de popular, polifónica o aun carnavalesca, y existen varios personajes que se presentan por sí mismos, como las máscaras del carnaval."

${ }^{12}$ No original: "[... el autor de un enunciado no se expresa nunca directamente, sino que pone en escena en el mismo enunciado un cierto número de personajes.”

${ }^{13}$ No original: "[...] en un mismo enunciado hay presentes varios sujetos con status linguísticos diferentes."

${ }^{14}$ No original: "[...] la frase, y por lo tanto la lengua, contiene alusiones a la actividad del habla, contiene alusiones sobre lo que hacemos cuando hablamos."
} 
O sentido, nessa teoria, é constituído de dois elementos: (1) a apresentação dos pontos de vista dos diferentes enunciadores; e (2) a indicação da posição do locutor em relação aos enunciadores (DUCROT, 1990, p. 66). Já a significação é constituída pelo conjunto de instruções que a frase dá a quem interpreta seus enunciados (DUCROT, 1990, p. 71).

Ducrot alerta que para uma compreensão adequada da noção de polifonia é preciso afastá-la da possibilidade de relatar, em um discurso, o discurso de um outro (em estilo direto ou indireto).

Não é suficiente, de fato, para que a gente possa falar em polifonia, que seja questão em um discurso atribuído a um locutor $L$, um discurso de uma outra pessoa L', porque a presença da fala de L' na de $L$ pode ser um simples discurso relatado, e isso exclui, de acordo comigo, a polifonia' ${ }^{15}$ (DUCROT, 1980, p. 44, tradução nossa).

Isso porque o semanticista dedica-se a uma forma de polifonia que ocorre no nível dos enunciadores, não no nível dos locutores (BARBISAN; TEIXEIRA, 2002, p. 168). O exemplo (8) ilustra a forma de polifonia que ocorre no nível dos enunciadores.

(8) Faz tempo bom, mas estou indisposto.

Nesse enunciado, é possível identificar quatro enunciadores: $E_{1}$ que expressa o tempo bom; $E_{2}$ que justifica o convite para um passeio a partir de tempo bom; $E_{3}$ que alega indisposição, e $E_{4}$ que conclui, a partir da indisposição, por não fazer o passeio.

Considerando que o sentido, segundo a Teoria da Polifonia, decorre de duas ações: $1^{\mathrm{a}}$ - da apresentação dos pontos de vista dos diferentes enunciadores; e $2^{\mathrm{a}}$ - da indicação da posição do locutor em relação aos enunciadores (DUCROT, 1990), é preciso explicitar quais atitudes o locutor pode tomar em relação a eles, que são: (a) assumir; (2) concordar; e (3) recusar. Dito de outra forma: "O locutor pode, primeiramente, identificar-se com um dos enunciadores, como no caso da asserção."16 (DUCROT, 1990, p. 66 , tradução nossa). Nesse caso, o locutor se identifica com um enunciador e

\footnotetext{
${ }^{15}$ No original: "Il ne suffit pas, en effet, pour que l'on puisse parler de polyphonie, qu'il soit question, dans le discours attribué à un locuteur L, d'un discours d'une autre personne L', car la présence de la parole de L' dans celle de L peut relever au simple discours rapporté, et cela exclut, selon moi, la polyphonie.

${ }^{16}$ No original: "El locutor puede en primer lugar identificarse con uno de los enunciadores, como es el caso de la aserción."
} 
atribui à sua enunciação o ponto de vista desse enunciador. Já a concordância do locutor com um enunciador se dá quando "[... ] o locutor indica que está de acordo com esse enunciador mesmo quando o enunciado não tem como objetivo fazer admitir o ponto de vista deste enunciador." ${ }^{17}$ (DUCROT, 1990, p. 66, tradução nossa). Para mostrar as diferenças entre as duas atitudes possíveis do locutor, aqui já apresentadas, trazemos o seguinte exemplo:

(9) João deixou o trabalho

A concepção polifônica de sentido indica a presença de dois enunciadores: um que afirma que João tinha um trabalho; e outro que alega João não ter um trabalho agora. Aqui, o locutor aceita a afirmação do primeiro enunciador, mas assume o que é dito pelo segundo.

A terceira atitude do locutor, que o semanticista apresenta como possível frente aos enunciadores, é a oposição, isto é, “[... ] rejeitar seu ponto de vista."18 (DUCROT, 1990, p. 67, tradução nossa).

Feita essa explanação, incapaz de esgotar o potencial da Teoria da Polifonia, acreditamos ser possível, agora, apresentar dois casos de polifonia referidos e exemplificados por Ducrot, são eles: a negação e a pressuposição.

\subsubsection{A negação}

O conceito de pressuposição, fundamentado pela noção de atitudes do locutor frente a diferentes enunciadores, permite caracterizar todo enunciado negativo como um confronto de dois enunciadores. No primeiro capítulo da obra Polifonía y Argumentación: conferencias del seminario Teoría de la Argumentación y Análisis del Discurso (1990), o semanticista argumenta: “Direi que em um enunciado negativo não- $P$ há no mínimo dois enunciadores: um primeiro enunciador $E_{1}$ que expressa o ponto de vista representado por $P$, e um segundo enunciador $E_{2}$ que rejeita esse ponto de vista." ${ }^{19}$ (DUCROT, 1990, p. 23, tradução nossa). Assim, o enunciado negativo é uma pequena peça de teatro que apresenta dois enunciadores em oposição um ao outro, quer dizer:

\footnotetext{
${ }^{17}$ No original: "[... ] el locutor indica que está de acuerdo con ese enunciador aun si el enunciado no tiene como objetivo hacer admitir el punto de vista de ese enunciador."

${ }^{18}$ No original: "[... ] de rechazar su punto de vista."

${ }^{19}$ No original: "Diré que en un enunciado negativo no-P hay por lo menos dos enunciadores: un primer enunciador $E_{1}$ que expresa el punto de vista representado por $P, y$ un segundo enunciador $E_{2}$ que presenta un rechazo de ese punto de vista."
} 
"É peculiar à negação que decifremos nela a afirmação do que nega ${ }^{20}$." (DUCROT, 1980, p. 53, tradução nossa). Possivelmente, o leitor deste artigo possa lembrar que, Machado de Assis já anunciava tal fundamento no século XIX: “E digo mal, porque negar é ainda afirmar [...]” (ASSIS, 2000, grifo nosso).

A concepção polifônica da negação permeia diferentes trabalhos de Ducrot (1980, 1987, 1990, entre outros). O semanticista (1987, p. 203) afirma distinguir três tipos de negação: (a) metalinguística; (b) polêmica; e (c) descritiva. Para estabelecer essa distinção, Ducrot se baseou em testes linguísticos. Desse modo, verificou que a negação, às vezes, mantém pressupostos do enunciado positivo e, outras vezes, os põem em dúvida. (BARBISAN; TEIXEIRA, 2002). Como não se tem o objetivo de descrever os casos de negação, mas apenas reafirmar a presença da descrição polifônica inerente à negação, não se trará todos os tipos de negação, passando-se de imediato à pressuposição.

\subsubsection{Pressuposição}

Na obra O dizer e o dito (1987), de Ducrot, dois capítulos são dedicados a explicar a noção de pressuposição. O capítulo I, "Pressupostos e subentendidos: a hipótese de uma Semântica Linguística”, foi publicado originalmente em 1969 e, naquele momento, Ducrot afirmava que o pressuposto é apresentado como uma evidência, como um elemento do universo do discurso, mas alerta: “[...] o pressuposto não pertence ao enunciado da mesma forma que o posto. Contudo, também ele lhe pertence embora isso ocorra de um outro modo." (DUCROT, 1987, p. 20). A identificação dos pressupostos não depende da reflexão individual de um usuário de língua, mas está inscrita na língua. Já o capítulo II da mesma obra, "Pressupostos e subentendidos (reexame)", foi publicado originalmente em 1977 como uma espécie de autocrítica em relação ao texto de 1969. Mantendo as indicações aqui citadas, Ducrot acrescenta que: "Se uma frase, em virtude dos critérios clássicos, pressupõe $X$, todos os enunciados também $O$ pressupõem, quando lhes é aplicado o critério novo, o do encadeamento." (DUCROT, 1987, p. 39), mesmo que o inverso não seja verdadeiro. O enunciado (10) pode ajudar a explicar essa questão:

\footnotetext{
${ }^{20}$ No original : Il est propre à la négation que l'on déchiffre en elle l'assertion de ce qu'elle nie.
} 
(10) Joaquim continua trabalhando

No nível da frase, temos como pressuposto a ideia de que Joaquim trabalhou em um tempo $X$ e permanece trabalhando num tempo posterior $X$ '. Admitindo-se coerente a explicação dada na descrição polifônica do enunciado (10), descrevemos os dois enunciadores presentes: $E_{1}$ afirma que Joaquim tinha um trabalho; e $\mathrm{E}_{2}$ atesta que Joaquim está trabalhando.

Nesse caso, o locutor aceita $E_{1}$ e assume o ponto de vista de $E_{2}$. É esse jogo de atitudes do locutor, diante de cada enunciador, que constitui o sentido de (10).

Uma última consideração acerca da pressuposição no nível do enunciado se faz necessária. A pressuposição, como inscrita na língua, impõe certas possibilidades de continuação do discurso e restringe outras. Em (10), o alocutário poderia responder sim ou não, mantendo os pressupostos, mas estaria impedido de responder algo como: portanto nunca trabalhou, sem rejeitar os pontos de vista apresentados.

As explicações e exemplificações até aqui realizadas parecem suficientes para aproximar o leitor dos fundamentos basilares da TAL e da Teoria da Polifonia, emergentes para a análise a seguir.

\section{Análise polifônica}

Este tópico pretende realizar a análise polifônica de duas falas do conto A Cartomante de Machado de Assis.

A primeira é da personagem Rita, envolvida no triângulo amoroso machadiano, retirada do início do conto, mais precisamente do momento em que Rita relata a Camilo, outro personagem desse triângulo amoroso, seu amante, a consulta que fez a uma cartomante.

A segunda fala é a de Camilo, retirada da parte final do conto, quando Camilo agradece à Cartomante, após ela ter terminado a leitura das cartas. A análise não pretende esgotar a apresentação de todas as situações polifônicas presentes nas falas, dada a extensão da descrição, mas mostrar como o diálogo polifônico precisa ser considerado para que se possa chegar ao sentido do discurso. 
Rita

(11) Não diga isso, Camilo. Se você soubesse como eu tenho andado, por sua causa. Você sabe; já lhe disse. Não ria de mim, não ria... (ASSIS, 2000, p. 5)

Inicialmente, constatamos a presença de uma negação, quer dizer, a presença de dois enunciadores, uma voz que ordena diga e uma segunda voz que ordena não diga. A ideia de ordem se localiza na atualização feita pelo locutor no modo imperativo. Nesse caso, locutor aceita o primeiro enunciador, mas assume o ponto de vista que nega.

$\mathrm{Na}$ atualização do modo subjuntivo, na sequência, encontramos dois enunciadores, o primeiro que afirma você sabe; e o segundo que nega a afirmação e anuncia você não sabe. Negação atualizada pelo locutor, quando mobiliza a forma se soubesse, convidando o alocutário a aceitar o discurso como uma hipótese. O locutor aceita o ponto de vista do primeiro enunciador você sabe, mas, novamente, assume o ponto de vista do enunciador que nega, isto é, você não sabe.

Na sequência da fala de Rita, temos a presença de um enunciador que se opõe à ideia assumida pelo locutor anteriormente. Na tentativa de refutar o ponto de vista já assumido, o locutor mobiliza novamente o enunciador que afirma você sabe, justificando tal ponto de vista com a afirmação já lhe disse. O locutor assume um ponto de vista que poderia ser parafraseado por já lhe disse, portanto tu sabes. A fala de Rita é encerrada pela repetição não ria de mim, em que encontramos duas vozes, a primeira que ordena ria e a segunda que ordena não ria. A Semântica Argumentativa assume que: "Para o sentido, é evidente que a simples repetição da palavra confere à sua segunda aparição um matiz de irritação ou de súplica ausente na primeira." (DUCROT,1970, p. 70). Em síntese, o locutor atualiza no discurso um sentido de irritação diante da ideia atualizada pelo locutor que poderia ser parafraseada por você sabe que estou preocupada por causa de nossa traição e, mesmo assim, ri de mim.

Analisemos agora a fala de Camilo.

(12) a senhora restitui-me a paz ao espírito, disse ele estendendo a mão por cima da mesa e apertando a da cartomante (ASSIS, 2000, p.22)

Inicialmente, temos um enunciador que afirma que é possível ter paz de espírito; um segundo enunciador afirma que é possível perder a paz de espírito e um terceiro enunciador, afirma que é possível retomar a paz de 
espírito após tê-la perdido, vozes justificadas pela atualização de restitui-me. Além disso, esse primeiro enunciado ainda apresenta outros dois pontos de vista: um que afirma que outra pessoa pode restituir a paz de espírito a alguém, e um segundo ponto de vista, que afirma a possibilidade de retomar a paz de espírito com a ajuda de outra pessoa.

No segundo enunciado, temos um enunciador ${ }^{21}$ que afirma que Camilo e a Cartomante estão um em frente ao outro; um segundo enunciador que afirma que os personagens estão separados por uma mesa; um terceiro enunciador que afirma que a largura da mesa permite aos personagens um toque de mão; um quarto enunciador que afirma que Camilo toma a iniciativa de estender a mão à Cartomante; um sexto enunciador que afirma que a Cartomante aceita o aperto de mão; e um sétimo enunciador que afirma que o aperto de mão confirma a gratidão de Camilo à Cartomante pelo fato de ela ter Ihe devolvido a paz ao espírito, enunciador que o locutor assume.

\section{Algumas considerações}

A Cartomante, no conto machadiano, afirma que "[...] há muita cousa misteriosa e verdadeira neste mundo.” (ASSIS, 2000, p. 7). Assim como ela, esperamos, neste estudo, ter demonstrado algumas das verdades que a língua pode revelar sobre o mundo, comprovando que uma análise semântica como a aqui proposta, quer dizer, uma análise essencialmente fundamentada na língua, permite mostrar o sentido de um enunciado/discurso por meio das relações inter e intra enunciados, sem recorrer a elementos externos à língua ou, como refere Saussure:

No que concerne à Lingüística interna, as coisas se passam de modo diferente: ela não admite uma disposição qualquer; a língua é um sistema que conhece somente sua ordem própria. Uma comparação com o jogo de xadrez fará compreendê-lo melhor. Nesse jogo, é relativamente fácil distinguir o externo do interno; o fato de ele ter passado da Pérsia para a Europa é de ordem externa; interno, ao contrário, é tudo quanto concerne ao sistema e às regras. Se eu substituir as peças de madeira por peças de marfim, a troca será indiferente para o sistema; mas se eu reduzir ou aumentar o número de peças, essa mudança atingirá profundamente a 'gramática' do jogo. [...] é interno tudo quanto provoca mudança do sistema em qualquer grau." (SAUSSURE, 2006, p. 31-32).

21 Procuramos fazer um deslocamento das ferramentas postas à disposição pela Teoria da Polifonia, de Oswald Ducrot para a descrição polifônica deste discurso. 
Esperamos, também, ter mostrado como é pela língua, pela atualização que o locutor faz, que são permitidas ou restringidas determinadas continuidades de um enunciado/discurso, tanto ao locutor, na continuidade de seu discurso, como ao alocutário, em resposta ao locutor.

Esta análise pode ser sintetizada por Wittgenstein que afirma que “[...] pois não [se] vê na essência algo que já é evidente e que se torna claro por meio de uma ordenação. Mas algo que se encontra abaixo da superfície. Algo que se encontra no interior, que vemos quando desvendamos a coisa e que uma análise deve evidenciar." (WITTGENSTEIN, 1999, p. 62). O sentido, assim como a traição machadiana, muitas vezes, não é algo tão evidente, mas pode ser desvendado. Uma análise semântico-argumentativa pode colaborar para revelar como se constitui o processo argumentativo, além de evidenciar tramas que não estão na superfície do discurso, mas impregnadas no interior do sistema da língua.

\section{Referências}

ANSCOMBRE, Jean-Claude; DUCROT, Oswald. La Argumentación en la lengua. Editorial Gredos, S.A.: Madrid, 1994.

AZEVEDO, Tânia Maris. Aprendizagem da compreensão leitora: uma proposta de transposição didática da Teoria da Polifonia e da Teoria dos Blocos Semânticos. Signo, Santa Cruz do Sul, v. 44, n. 80, jul. 2019.

ASSIS, Machado de. A Cartomante. [S.I.], Sivadi Editorial, 2000.

BARBISAN, Leci Borges. O sentido no discurso: o olhar da Teoria da Argumentação na Língua. In: DI FANTI, Maria da Glória; BARBISAN, Leci Borges (org.). Enunciação e Discurso: tramas e sentidos. São Paulo: Contexto, 2012.

BARBISAN, Leci Borges. TEIXEIRA, Marlene. Polifonia: origem e evolução do conceito em Oswald Ducrot. Organon, Porto Alegre, v. 16, n.32/33, p. 161-180, 2002.

DUCROT, Oswald. Polifonía y argumentación: conferencias del seminario Teoría de la Argumentación y Análisis del Discurso. Cali: Universidad del Valle, 1990.

. Estruturalismo e Lingüística. São Paulo: Cultrix, 1970.

. Les mots du discours. Paris: Minuit, 1980. 
. O dizer e dito. Campinas: Pontes, 1987.

. Prefácio. In: VOGT, Carlos. O intervalo semântico. 2.ed. São Paulo: Campinas: Ateliê Editorial; Editora da Unicamp, 2009.

- Trajetória e legado de um filósofo da linguagem: Oswald Ducrot. Revista Investigações, v. 25, n. 2, p. 11-17, jul. 2012.

SAUSSURE, Ferdinand de. Curso de linguística geral. 27. ed. São Paulo: Cultrix, 2006.

WITTGENSTEIN, Ludwig. Investigações filosóficas. São Paulo: Nova Cultural, 1999.

\section{Forma de citação sugerida}

CEREZOLI, Andréia Inês Hanel; NIEDERAUER, Carina Maria Melchiors. A cartomante: do triângulo amoroso machadiano à trama argumentativa. EID\&A - Revista Eletrônica de Estudos Integrados em Discurso e Argumentação, Ilhéus, n. 19, v. 2, p. 3-17, dez.2019. DOI 10.17648/eidea-19-v2-2383. 